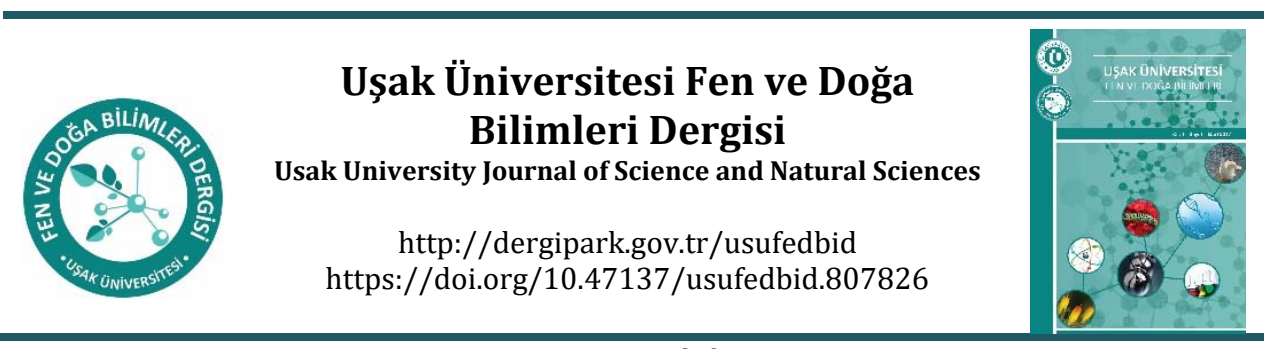

Araştırma makalesi

\title{
Uşak İli Peyzaj Florası: Atapark Parkı Peyzaj Florası Taksonları Değerlendirmesi
}

\author{
Mehtap Dönmez Şahin \\ Matematik ve Fen Bilimleri Eğitimi Bölümü, Eğitim Fakültesi, Uşak Üniversitesi, Uşak, Türkiye
}

\begin{abstract}
Urbanization has brought concretization with it. In recent years, the importance of parks and gardens in the city for recreation and sports has increased. Plants found in these areas can be of both natural and exotic origin. The parks contain many landscape plants. In order for these plants to survive in the planted area, their adaptation, homeland, soil requirements, adaptation to the climate, water needs and flowering time are very important. In Atapark Park in the center of Ușak, there are all of the landscape plant taxa in the parks in Uşak. 99 taxa have been identified in Atapark Park and these taxa have been evaluated in terms of their ecological demands and characteristics.
\end{abstract}

Keywords: Ecology, Landscape Flora, Urban Ecology, Atapark Park, Uşak.

\section{Özet}

Kentleşme, betonlaşmayı da beraberinde getirmiştir. Son yllarda şehir içindeki park ve bahçelerin dinlenme ve spor yapma amaçlı önemi artmıştır. Bu alanlarda bulunan bitkiler, hem doğal, hem de egzotik kökenli olabilmektedir. Parklar birçok peyzaj bitkisini içermektedir. Bu bitkilerin dikilen yerde hayatlarını devam ettirebilmeleri için, adaptasyonları, anavatanları, toprak istekleri, iklimle uyumu, su ihtiyaçları, çiçeklenme zamanları çok önemlidir. Uşak İli merkezinde bulunan Atapark Parkı'nda Ușak ili'nde parklarında bulunan peyzaj bitkileri taksonlarının tümü bulunmaktadır. Atapark Parkı'nda 99 takson tespit edilmiş ve bu taksonlar, ekolojik istekleri ve özellikleri bakımından değerlendirilmiştir.

Anahtar Kelimeler: Ekoloji, Peyzaj Florası, Kent Ekolojisi, Atapark Parkı, Uşak.

(C)2020 Usak University all rights reserved.

\section{Giriş}

Dünya üzerinde sanayi devriminden sonra insan nüfusu kentlerde artış göstermiştir. Artan nüfusla beraber kentlerde ekolojik sorunlar ortaya çıkmıştır. Kent ekolojisi içindeki $\underline{\text { doğal ve yapay ekosistemlerde, hava, su, toprak, bitkiler, mikroorganizmalar, yollar, }}$

\footnotetext{
*Corresponding author:

E-mail: mehtap.sahin@usak.edu.tr

ORCID ID: 0000-0002-6081-6699
}

(C)2020 Usak University all rights reserved. 
binalar, turizm hizmetleri bulunmaktadır. Kent ekosisteminde doğal unsurların, doğal yapısının bozulması ve giderek yapay ekosistemlerin çevrelerinde artış göstermesi nedeniyle, insanlar doğal ekosistemin sürdürülebilirliğinin ihtiyacı ve önemini kavradıkları için, kentlerde park ve bahçelere önem verip, yer ayırmışlardır [1].

"Park, sözlük anlamıyla, bir yerleşim merkezinde halkın gezip hava alması için düzenlenmiş ağaçlı ve çiçekli bahçe olarak" tanımlanmıştır [2]. Kent içerisinde park ve bahçeler, genellikle birçok bitki taksonu içeren, betonlaşmalar arasında yeşil alanlar, kenti soğutan hava akımlarının dolaşmasına izin veren yerler, hava temizleme ve soğutma, ışığı soğurma, büyüklüklerine göre su döngüsü ve yer altı suyuna katkıda bulunan yerlerdir [3]. Ayrıca özellikle de arılara ve kuşlar başta olmak üzere hayvanlara da ev sahipliği yapan alanlardır. Doğal yapısı gereği, doğanın bir parçası olan insanın, moral bulduğu, stres attığı, dinlendiği, yürüyüş yaptığı, insanın ihtiyacı olan yerlerdir. Bu alanların en büyük bileşeni bitkilerdir.

Park ve bahçelerin peyzajında kullanılan bitkilerin özellikleri vardır. Bu özellikleri şöyle sıralayabiliriz; fazla bakım istememeleri, sıcağa ve kuraklığa dayanıklı olmaları, estetik güzellikleri olması, dış yapıları, yaprak, çiçek, meyveleri itibariyle yıl boyunca farklı renk görünümde olmalarıdır [4].

Çeşitli nedenlerle kent nüfusunun giderek arttığı günümüze, insanlar dinlenme, eğlenme, spor yapma amaçlı park ve bahçelere ihtiyaç duymaktadır. Bu nedenle de park ve bahçe gereksinimi ve önemi de artmıştır. Park ve bahçelerde bulunan bitkiler peyzaj amaçlı bitkilerin hava kirliliğine, insan baskısına, sulama azlığına dayanıklı, estetiği ve kokusu güzel, kalıcı, iklimle uyumlu olması istenir ve beklenir [5].

Uşak İl Merkezinde 200 adet park vardır. Uşak'ta kişi başına düşen yeşil alan miktarı 8, $33 \mathrm{~m}^{2}$ dir. Atapark Uşak il merkezinde, etrafında otoyol ve bisiklet yolunun, doğu kısmında alışveriş merkezi ve Atatürk Kültür Merkezinin, içerisinde spor aletleri ve yürüme yolunun, otopark, çay bahçelerinin ve havuzun bulunduğu, her gün binlerce kişinin ziyaret ettiği daire şeklinde parktır. Parkın bitkilerin bulunduğu alan yaklaşık $80.000 \mathrm{~m}^{2}$ dir. Uşak İli Parklarında bulunan bütün taksonlar Atapark'ta bulunmaktadır [6].

$\mathrm{Bu}$ araştırmayı yapmaktaki amacımız, Uşak'ta Atapark nezlinde, peyzajda kullanılan bitkiler, iklimle uyumlumudur? Gelecekte küresel iklim değişikliği ile sıcaklığın ve kuraklığın arttığı dönemde peyzajda kullanılan bitkiler hala varlıklarını devam ettirebilecek midir? Yoksa şimdiden peyzaj florasını değiștirmek mi gerekir? sorularına yanıt aramak ve daha önce hiç çalışılmamış olan, Uşak ili peyzaj florasını tespit ederek, Uşak ili biyoçeşitliliğini kayıt altına almaktır.

\subsection{Araştırma Bölgesinin İklimi}

$38^{\circ} 41^{\prime \prime} \mathrm{K}$ ve $29^{\circ} 41^{\prime \prime} \mathrm{D}$ boylamında bulunan Uşak İli rasat istasyonu 919 m yüksekliktedir. Uşak'ta yıllık sıcaklık $13{ }^{\circ} \mathrm{C}$ dir. Uşak İli yağış rejim tipi mevsimlere göre, Kış $(\% 40,6)$, İlkbahar (\%29,7), Sonbahar (\%21,4), Yaz $(\% 8,3)$ olarak siralanır demek, KISY şeklindedir. Meteoroloji verilerinden çıkan verilere göre Uşak ili biyoiklim katı, Emberger 
fomülüne göre hesap edildiğinde(Akman, 1990), Q=58,41 ve $m=-1,5$ değeriyle Uşak ili iklimi kışı soğuk, yarı kurak, Akdeniz İklimi özelliklerini gösterir [7,8].

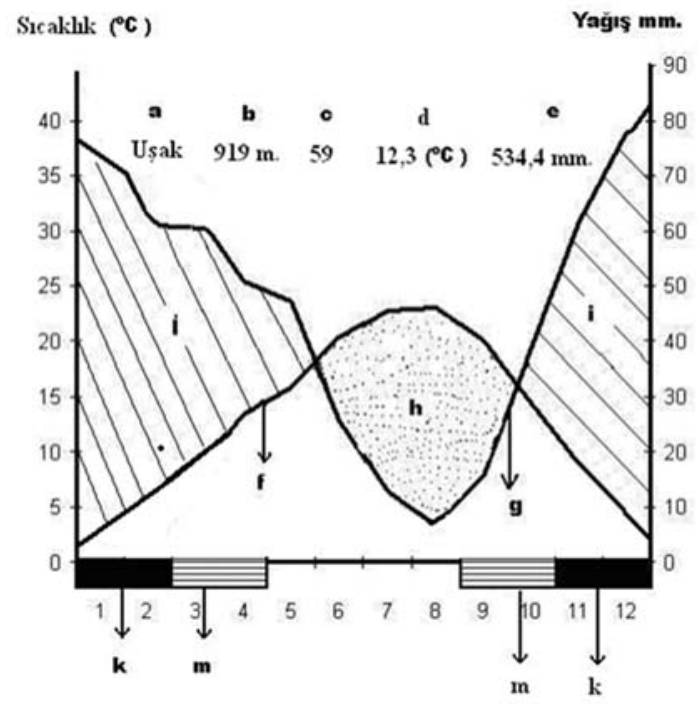

Şekil 1. Uşak İli'nin ombrotermik iklim diyagramı [7]

a-Meteoroloji istasyonunun yeri ve yüksekliği, b-İstasyonun rakımı, c-Rasat süresi, dYıllık ortalama sıcaklık $(\stackrel{\circ}{\circ} \mathrm{C}$ ), e-Yıllık ortalama yağış $(\mathrm{mm})$, f-Sıcaklık eğrisi (aylık ortalamalara göre), g-Yağıș eğrisi (aylık ortalamalara göre), h-Kurak periyot i-Yağışlı periyot, k-Donlu günler, m-Don olma ihtimali olan aylar

\section{Materyal ve Metot}

\subsection{Toprak Analizleri Metodu}

Toprakların fiziksel ve kimyasal özelliklerini araştırmak ve topraklarla çeşitli bitki birlikleri arasındaki ilişkileri tesbit etmek amacıyla parklardan geniş muhtelif yerlerden 0-20 cm ile 20-40 cm'ye kadar olan derinliklerden toprak örnekleri alınmıştır. Toprak analizleri, Ege Üniversitesi, Ziraat Fakültesi, Toprak Bölümü Laboratuvarlarında yapılmıştır. Toprak analizlerinde, fiziksel analizler ve kimyasal analizler yapılmıștır. Fiziksel analizlerde, kil, silt, kum, tekstür, kimyasal analizlerde, Elektriksel iletkenlik, toplam tuz, kireç, fosfor, organik madde, ph tespiti yapılmıştır $[9,10]$.

\subsection{Bitki Toplama Metodu}

Atapark Parkı Uşak İli, kent merkezinde bulunan, bakımı Uşak ili Uşak belediyesine bağlı parktır. Bu parktan, 2019 yıllarında farklı mevsimlerde araştırma alanından toplanan bitki örnekleri herbaryum tekniklerine göre kurutulmuştur [11]. Daha sonra ilgili flora kitaplarının ışığında teşhisleri yapılmıştır. Uşak Belediyesi park ve bahçeler birimi yetkileri ile görüşülmüş, en fazla Atapark parkında bitki taksonu bulunduğu ve bütün parklarda bulunan bitkilerin Atapark parkında bulunduğu teyidi alınmıştır. 


\section{Bulgular}

\subsection{Toprak Analizi Bulguları}

Tablo 1. Araştırma alanının toprak analizleri bulguları

\begin{tabular}{|c|c|c|c|c|c|c|l|l|l|}
\hline & \multicolumn{2}{|c|}{ Anaziksel } & \multicolumn{3}{c|}{ Kimyasal } & \multicolumn{3}{c|}{ Analizler } \\
\hline $\begin{array}{l}\text { Derinlik } \\
\mathrm{cm}\end{array}$ & Kum \% & $\begin{array}{l}\text { Mil } \\
0\end{array}$ & Kil\% & Bünye & $\mathrm{Ph}$ & Kireç & $\begin{array}{l}\text { organik } \\
\text { mad.\% } \%\end{array}$ & $\begin{array}{l}\text { toplam.N } \\
\%\end{array}$ & $\begin{array}{l}\text { alınabilir } \\
\text { K ppm }\end{array}$ \\
\hline $0-20$ & 46,4 & 22 & 31,6 & $\begin{array}{l}\text { Kumlu- } \\
\text { Killi-Tın }\end{array}$ & 7,64 & 8,87 & 1,32 & 0,084 & 421,4 \\
\hline $20-40$ & 52,4 & 14 & 33,6 & $\begin{array}{l}\text { Kumlu- } \\
\text { Killi-Tın }\end{array}$ & 7,67 & 8,38 & 1,32 & 0,078 & 298,9 \\
\hline
\end{tabular}

Araştırma alanında bitkilerin bulunduğu topraktan alınan üst $(0-20 \mathrm{~cm})$ ve alt $(20-40 \mathrm{~cm})$ topraklar, Ege Üniversitesi, Ziraat Fakültesi, Toprak Bölümünde yapılan toprak analizler ettirilmiştir. Analiz sonuçlarına bakıldığında, alt ve üst toprağın bünyesinin Kumlu-KilliTın olduğu görülmektedir. Toprakların asitlik derecelerine bakıldığında iki katman toprağın da hafif alkali olduğu görülmektedir. Kireç bakımından değerlendirildiğinde iki katman toprak ta orta kireçli sınıfındadır. Organik madde bakımından değerlendirildiğinde toprak katmanlarının ikisi de, organik madde bakımından fakirdir. Toplam $\mathrm{N}$ bakımından değerlendirildiğinde, toprak katmanlarında bulunan $\mathrm{N}$ un az olduğu görülmektedir. Alınabilir K bakımından toprak katmanların analiz sonuçlarına bakıldığında da, alınabilir K (ppm) un fazla olduğu değerlendirilmesi ilgili parametrelere bakıldığında görülmüştür (Tablo 1) [9,10].

\subsection{Flora Analizi Sonuçları}

Uşak İli merkezinde bulunan Atapark Parkı'ndan bitkinin formuna göre toplanan yaprak, çiçek, kök, gövde, meyve içeren bitki örnekleri, herbaryum metoduna göre kurutulmuş ve Dr. Öğretim Üyesi Mehtap Dönmez Şahin tarafından, ilgili flora kitap ve literatür kaynağı yardımıyla teşhis edilmiştir [11,12,13,14].

Uşak ili Atapark parkında bulunan bitki taksonları tabloda verilmiştir. 
Tablo 2. Uşak Merkez Atapark Parkı Peyzaj Florası.

\begin{tabular}{|c|c|c|c|c|c|c|c|c|}
\hline & $\begin{array}{l}\text { LATINCE } \\
\text { ADI- } \\
\text { ALANDAN } \\
\text { TOPLAMA } \\
\text { TARIHİ }\end{array}$ & TÜRKÇE ADI & TÜRÜ & $\begin{array}{l}\text { DOĞAL } \\
\text { YAYILIŞ }\end{array}$ & FAMILYA & $\begin{array}{l}\text { TOPRAK } \\
\text { İSTEĞİ }\end{array}$ & $\begin{array}{l}\text { SU } \\
\text { ISTE } \\
\text { Ği }\end{array}$ & $\begin{array}{l}\text { ÇIÇEK- } \\
\text { LENME } \\
\text { ZAMANI }\end{array}$ \\
\hline 1 & $\begin{array}{l}\text { Acer } \\
\text { platanoides } \\
\text { L."crimson } \\
\text { sentry" } \\
\text { "bushy", } \\
4.05 .2019, \\
\text { MD\$̧1520. }\end{array}$ & $\begin{array}{l}\text { Çınar yap. } \\
\text { Akçaağaç. }\end{array}$ & Ağaç & $\begin{array}{l}\text { Trakya, } \\
\text { Marmara, Ege } \\
\text { ve Karadeniz }\end{array}$ & Acereceae & Kumlu-killi & Orta & Nisan \\
\hline 2 & $\begin{array}{l}\text { Acer } \\
\text { platanoides } \\
\text { L. "crimson } \\
\text { king" } \\
5.05 .2019 \text {, } \\
\text { MDŞ } 1525 .\end{array}$ & $\begin{array}{l}\text { Çınar yap. } \\
\text { Akçaağaç }\end{array}$ & Ağaç & $\begin{array}{l}\text { Trakya, } \\
\text { Marmara, Ege } \\
\text { ve Karadeniz }\end{array}$ & Acereceae & Kumlu-killi & Orta & Nisan \\
\hline 3 & $\begin{array}{l}\text { Acer } \\
\text { palmatum } \\
\text { Thunb. } \\
\text { "dissectum } \\
\text { atropurpur } \\
\text { eum" } \\
5.05 .2019 \text {, } \\
\text { MDŞ } 1526 .\end{array}$ & $\begin{array}{l}\text { Japon } \\
\text { akçaağacı }\end{array}$ & Ağaç & $\begin{array}{l}\text { Japonya, Kore } \\
\text { ve Çin }\end{array}$ & Acereceae & $\begin{array}{l}\text { Kumlu-killi- } \\
\text { hafif asitli }\end{array}$ & Fazla & $\begin{array}{l}\text { Haziran- } \\
\text { Temmuz }\end{array}$ \\
\hline 4 & $\begin{array}{l}\text { Acer } \\
\text { palmatum } \\
\text { Thunb. } \\
\text { "atropurpu } \\
\text { reum" } \\
7.05 .2019, \\
\text { MDŞ } 1527 .\end{array}$ & Alev akçaağaç & Ağaç & $\begin{array}{l}\text { Japonya, Kore } \\
\text { ve Çin }\end{array}$ & Acereceae & $\begin{array}{l}\text { Humuslu - } \\
\text { asidik }\end{array}$ & Fazla & $\begin{array}{l}\text { Nisan- } \\
\text { Mayıs }\end{array}$ \\
\hline 5 & $\begin{array}{l}\text { Acer } \\
\text { saccharinu } \\
m \text { L. } \\
\text { 4.05.2019, } \\
\text { MDŞ 1521. }\end{array}$ & $\begin{array}{l}\text { Şeker } \\
\text { akçaağacı }\end{array}$ & Ağaç & $\begin{array}{l}\text { Doğu ve orta } \\
\text { Amerika } \\
\text { Birleşik } \\
\text { Devletleri ve } \\
\text { güneydoğu } \\
\text { Kanada }\end{array}$ & Acereceae & Kumlu-Killi & Orta & Mart \\
\hline 6 & 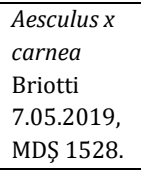 & $\begin{array}{l}\text { Kırmızı çiçekli } \\
\text { at kestanesi }\end{array}$ & Ağaç & Kuzey Amerika & Hippocastanaceae & Killi & Fazla & Mayıs \\
\hline 7 & $\begin{array}{l}\text { Aesculus } \\
\text { hippocastan } \\
\text { um L. } \\
7.05 .2019 \text {, } \\
1529 .\end{array}$ & $\begin{array}{l}\text { Beyaz çiçekli } \\
\text { akçaağaç }\end{array}$ & Ağaç & $\begin{array}{l}\text { Asya, } \\
\text { (Hindistan) }\end{array}$ & Hippocastanaceae & Kumlu-killi & Orta & Mayıs \\
\hline
\end{tabular}




\begin{tabular}{|c|c|c|c|c|c|c|c|c|}
\hline 8 & $\begin{array}{l}\text { Betula alba } \\
\text { L. } \\
4.05 .2019 \text {, } \\
\text { MDȘ } 1521 .\end{array}$ & Akhuş & Ağaç & $\begin{array}{l}\text { Kuzey Avrupa, } \\
\text { Kuzey Asya, } \\
\text { Türkiye }\end{array}$ & Betulaceae & Kumlu-Killi & $\mathrm{Az}$ & Nisan \\
\hline 9 & $\begin{array}{l}\text { Betula alba } \\
\text { L." } \\
\text { pendula" } \\
4.05 .2019 \text {, } \\
\text { MDS } 1522 .\end{array}$ & Sarkık huş & Ağaç & $\begin{array}{l}\text { Kuzey Avrupa, } \\
\text { Kafkasya, Doğu } \\
\text { ve Kuzey } \\
\text { Anadolu }\end{array}$ & Betulaceae & $\begin{array}{l}\text { Hafif asitli- } \\
\text { kumlu- } \\
\text { balçılılı }\end{array}$ & Orta & Nisan \\
\hline 10 & $\begin{array}{l}\text { Betula } \\
\text { pendula } \\
\text { Roth. } \\
\text { "Youngii" } \\
\text { 9.05.2019, } \\
\text { MDŞ 1529. }\end{array}$ & Sarkık huş & Ağaç & İngiltere & Betulaceae & Kumlu-killi & Orta & Mart \\
\hline 11 & $\begin{array}{l}\text { Carpinus } \\
\text { betulus L. } \\
5.05 .2019, \\
\text { MDȘ } 1535 .\end{array}$ & $\begin{array}{l}\text { Sütun formlu } \\
\text { gürgen }\end{array}$ & Ağaç & $\begin{array}{l}\text { İran, Kafkasya, } \\
\text { Türkiye(Marm } \\
\text { ara, Karadeniz, } \\
\text { Trakya) }\end{array}$ & Betulaceae & $\begin{array}{l}\text { Kumlu-Killi- } \\
\text { hafif asidik }\end{array}$ & Orta & Eylül \\
\hline 12 & $\begin{array}{l}\text { Catalpa } \\
\text { bignonoides } \\
\text { Walter } \\
4.05 .2019, \\
\text { MDŞ } 1523 .\end{array}$ & Buz ağacı & Ağaç & $\begin{array}{l}\text { Amerika, } \\
\text { Kanada }\end{array}$ & Bignonaceae & Humuslu & Orta & Haziran \\
\hline 13 & $\begin{array}{l}\text { Cercis } \\
\text { siliquastru } \\
m \text { L. } \\
10.05 .2019, \\
\text { MDŞ } 1536 .\end{array}$ & Erguvan & Ağaç & $\begin{array}{l}\text { Batı Asya ve } \\
\text { Güney Avrupa }\end{array}$ & Leguminosae & Kozmopolit & Orta & Mayıs \\
\hline 14 & $\begin{array}{l}\text { Cotinus } \\
\text { coggygria } \\
\text { Scop. } \\
\text { 10.05.2019, } \\
\text { MDŞ } 1557 .\end{array}$ & $\begin{array}{l}\text { Bulut(duman) } \\
\text { ağacı }\end{array}$ & Ağaç & Yaygın & Anacardiaceae & Kireçli & $\mathrm{Az}$ & $\begin{array}{l}\text { Haziran- } \\
\text { Temmuz }\end{array}$ \\
\hline 15 & $\begin{array}{l}\text { Crataeagus } \\
\text { laevigata } \\
\text { DC. } \\
\text { 10.05.2019, } \\
\text { MDŞ } 1537 .\end{array}$ & $\begin{array}{l}\text { Kırmızı çiçekli } \\
\text { alıç }\end{array}$ & Ağaç & Avrupa & Rosaceae & Kozmopolit & Orta & Mayıs \\
\hline 16 & $\begin{array}{l}\text { Crataegus } \\
\text { monogyna } \\
\text { Jacq. } \\
4.05 .2019 \text {, } \\
\text { MDŞ } 1524 .\end{array}$ & Alıç & Ağaç & $\begin{array}{l}\text { Türkiye, } \\
\text { Avrupa, Kıbrıs, } \\
\text { Suriye ve } \\
\text { Kuzey Irak }\end{array}$ & Rosaceae & Kozmopolit & Orta & Mayıs \\
\hline 17 & 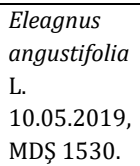 & İğde & Ağaç & Yaygın & Elaeagnaceae & Kumlu, Killi & $\mathrm{Az}$ & Haziran \\
\hline 18 & $\begin{array}{l}\text { Fraxinus } \\
\text { americana } \\
\text { L. } \\
\text { 10.05.2019, } \\
\text { MDŞ 1539. }\end{array}$ & $\begin{array}{l}\text { American } \\
\text { dişbudak }\end{array}$ & Ağaç & $\begin{array}{l}\text { Amerika, } \\
\text { Avrupa, } \\
\text { Kafkasya }\end{array}$ & Oleaceae & $\begin{array}{l}\text { Balçıklı } \\
\text { topraklar }\end{array}$ & Çok & $\begin{array}{l}\text { Nisan- } \\
\text { Mayis }\end{array}$ \\
\hline 19 & $\begin{array}{l}\text { Fraxinus } \\
\text { excelsior L. } \\
10.05 .2019, \\
\text { MDŞ } 1538 .\end{array}$ & Dişbudak & Ağaç & $\begin{array}{l}\text { Avrupa, Kırım, } \\
\text { Kafkasya } \\
\text { Türkiye }\end{array}$ & Oleaceae & $\begin{array}{l}\text { Akarsu } \\
\text { kenarları }\end{array}$ & Çok & $\begin{array}{l}\text { Nisan- } \\
\text { Mayis }\end{array}$ \\
\hline 20 & $\begin{array}{l}\text { Fraxinus } \\
\text { excelsior } \mathrm{L} . \\
\text { "pendula" }\end{array}$ & $\begin{array}{l}\text { Sarkık adi } \\
\text { dişbudak }\end{array}$ & Ağaç & $\begin{array}{l}\text { Batı Asya, } \\
\text { Türkiye. }\end{array}$ & Oleaceae & $\begin{array}{l}\text { Kumlu-tınlı } \\
\text { toprak }\end{array}$ & Çok & $\begin{array}{l}\text { Nisan- } \\
\text { Mayis }\end{array}$ \\
\hline
\end{tabular}




\begin{tabular}{|c|c|c|c|c|c|c|c|c|}
\hline & $\begin{array}{l}\text { 10.05.2019, } \\
\text { MDȘ } 1540 .\end{array}$ & & & & & & & \\
\hline 21 & $\begin{array}{l}\text { Ginkgo } \\
\text { biloba L. } \\
\text { 10.05.2019, } \\
\text { MDŞ 1531. }\end{array}$ & Mabed ağacı & Ağaç & Çin, Japonya & Ginkgoaceae & $\begin{array}{l}\text { Kumlu-tınlı } \\
\text { topraklar }\end{array}$ & Orta & Nisan \\
\hline 22 & 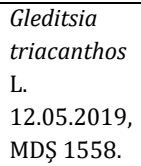 & Glediçya & Ağaç & Kuzey Amerika & Leguminosae & $\begin{array}{l}\text { Kumlu- tınlı } \\
\text { topraklar }\end{array}$ & Orta & $\begin{array}{l}\text { Mayıs- } \\
\text { Haziran }\end{array}$ \\
\hline 23 & $\begin{array}{l}\text { Hibiscus } \\
\text { syriacus L. } \\
10.06 .2019, \\
\text { MDŞ 1560. }\end{array}$ & Ağaç hatmi & Ağaç & Güney Kore. & Malvaceae & $\begin{array}{l}\text { Kumlu-Killi } \\
\text { topraklar }\end{array}$ & Orta & $\begin{array}{l}\text { Haziran- } \\
\text { Temmuz }\end{array}$ \\
\hline 24 & $\begin{array}{l}\text { Koelreuteri } \\
a \\
\text { paniculata } \\
\text { Laxm. } \\
10.06 .2019 \text {, } \\
\text { MDŞ } 1565 .\end{array}$ & $\begin{array}{l}\text { Güvey kandili } \\
\text { Fener ağacı }\end{array}$ & Ağaç & Çin, Kore. & Sapindaceae & Kumlu & $\mathrm{Az}$ & $\begin{array}{l}\text { Haziran - } \\
\text { Temmuz }\end{array}$ \\
\hline 25 & $\begin{array}{l}\text { Laburnum } \\
\text { vulgare } \\
\text { J.Presl. } \\
\text { 10.06.2019, } \\
\text { MDŞ } 1561 .\end{array}$ & $\begin{array}{l}\text { Dağ sarı } \\
\text { salkımı }\end{array}$ & Ağaç & Güney Avrupa & Genisteae & Kozmopolit & Orta & $\begin{array}{l}\text { Mayıs- } \\
\text { Haziran }\end{array}$ \\
\hline 26 & $\begin{array}{l}\text { Liquadamb } \\
\text { er } \\
\text { styraciflua } \\
\text { L. } \\
\text { 5.05.2019, } \\
\text { MDŞ } 1563 .\end{array}$ & Sığla ağacı & Ağaç & Amerika & Hamamelidaceae & Killi-Tınlı & Orta & $\begin{array}{l}\text { Nisan- } \\
\text { Mayis }\end{array}$ \\
\hline 27 & $\begin{array}{l}\text { Liriodendro } \\
n \text { tulipifera } \\
\text { L. } \\
04.05 .2019 \text {, } \\
\text { MDŞ } 1570 .\end{array}$ & Lale ağacı & Ağaç & $\begin{array}{l}\text { Kuzey, doğu } \\
\text { Amerika }\end{array}$ & Magnoliaceae & Killi-Tınlı & $\begin{array}{l}\text { Yüks } \\
\text { ek }\end{array}$ & $\begin{array}{l}\text { Nisan- } \\
\text { Mayis }\end{array}$ \\
\hline 28 & $\begin{array}{l}\text { Malus } \\
\text { adams L. } \\
04.05 .2019, \\
\text { MDŞ 1566. }\end{array}$ & Süs elması & Ağaç & Kuzey Anadolu & Rosaceae & Kumlu-tınlı & Orta & Mayıs \\
\hline 29 & $\begin{array}{l}\text { Malus } \\
\text { floribunda } \\
\text { L. } \\
\text { 8.04.2019, } \\
\text { MDŞ } 1568 .\end{array}$ & Süs elması & Ağaç & $\begin{array}{l}\text { Avrupa, Asya } \\
\text { ve Kuzey } \\
\text { Amerika }\end{array}$ & Rosaceae & Kumlu-Killi & Orta & Nisan \\
\hline 30 & $\begin{array}{l}\text { Morus alba } \\
\text { L."pendula" } \\
08.04 .2019, \\
\text { MDŞ 1575. }\end{array}$ & Sarkık dallı dut & Ağaç & Çin & Moraceae & Kumlu-tınlı & $\mathrm{Az}$ & $\begin{array}{l}\text { Mart- } \\
\text { Nisan }\end{array}$ \\
\hline 31 & $\begin{array}{l}\text { Platanus } \\
\text { acerifolia L. } \\
10.05 .2019, \\
\text { MDŞ 1559. }\end{array}$ & $\begin{array}{l}\text { Beyaz gövdeli } \\
\text { çınar }\end{array}$ & Ağaç & $\begin{array}{l}\text { Kuzey } \\
\text { Amerika, } \\
\text { Güney ve Doğu } \\
\text { Avrupa }\end{array}$ & Platanaceae & Humuslu & Fazla & Nisan \\
\hline 32 & $\begin{array}{l}\text { Platanus } \\
\text { orientalis L. } \\
05.05 .2019, \\
\text { MDŞ 1562. } \\
\end{array}$ & Doğu çınarı & Ağaç & Türkiye & Planaceae & Kumlu & Fazla & $\begin{array}{l}\text { Mart- } \\
\text { Nisan- } \\
\text { Mayis }\end{array}$ \\
\hline 33 & $\begin{array}{l}\text { Prunus } \\
\text { cerasifera } \\
\text { Ehrh. }\end{array}$ & $\begin{array}{l}\text { Alttan dallı } \\
\text { kırmızı erik }\end{array}$ & Ağaç & Avrupa & Rosaceae & $\begin{array}{l}\text { Killi-tınl, } \\
\text { hafif alkali }\end{array}$ & Orta & $\begin{array}{l}\text { Nisan- } \\
\text { Mayıs }\end{array}$ \\
\hline
\end{tabular}




\begin{tabular}{|c|c|c|c|c|c|c|c|c|}
\hline & $\begin{array}{l}\text { piss.nigra } \\
\text { "bushy" } \\
5.05 .2019, \\
\text { MDȘ 1589. }\end{array}$ & & & & & & & \\
\hline 34 & $\begin{array}{l}\text { Prunus } \\
\text { cerasifera } \\
\text { Ehrh piss. } \\
\text { nigra } \\
5.05 .2019 \text {, } \\
\text { MDŞ } 1588 .\end{array}$ & $\begin{array}{l}\text { Kırmızı } \\
\text { erik(dallı) }\end{array}$ & Ağaç & Avrupa & Rosaceae & $\begin{array}{l}\text { Killi-tınl, } \\
\text { hafif alkali }\end{array}$ & Orta & $\begin{array}{l}\text { Nisan- } \\
\text { Mayis }\end{array}$ \\
\hline 35 & $\begin{array}{l}\text { Prunus } \\
\text { serrulata } \\
\text { Lindl. "kiku } \\
\text { shidare } \\
\text { sakura" } \\
4.04 .2019 \text {, } \\
\text { MDŞ } 1590 .\end{array}$ & Süs kirazı & Ağaç & Asya & Rosaceae & Killi-tınlı & Orta & Nisan \\
\hline 36 & $\begin{array}{l}\text { Prunus } \\
\text { serrulata } \\
\text { Lindl. } \\
\text { "kanzan" } \\
\text { 04.05.2019, } \\
\text { MDŞ 1564. }\end{array}$ & $\begin{array}{l}\text { Japon çiçek } \\
\text { kirazı }\end{array}$ & Ağaç & Çin & Rosaceae & Kozmopolit & Frta & $\begin{array}{l}\text { Nisan- } \\
\text { Mayis }\end{array}$ \\
\hline 37 & $\begin{array}{l}\text { Quercus } \\
\text { robur L. } \\
8.04 .2019, \\
\text { MDȘ } 1579 .\end{array}$ & Meşe & Ağaç & $\begin{array}{l}\text { Avrupa, } \\
\text { Kafkasya, Çin, } \\
\text { Kuzey Amerika }\end{array}$ & Fagaceae & Humuslu & Fazla & Nisan \\
\hline 38 & $\begin{array}{l}\text { Quercus } \\
\text { rubra L. } \\
15.03 .2019, \\
\text { MDŞ 1591. }\end{array}$ & Meşe & Ağaç & $\begin{array}{l}\text { Kuzey } \\
\text { Amerika, } \\
\text { Kanada }\end{array}$ & Fagaceae & Kumlu-tınlı & $\mathrm{Az}$ & Mart \\
\hline 39 & $\begin{array}{l}\text { Rhus } \\
\text { typhina L. } \\
\text { "laciniata" } \\
\text { 10.06.2019, } \\
\text { MDŞ 1567. }\end{array}$ & Sumak & Ağaç & $\begin{array}{l}\text { Kuzey } \\
\text { Amerika, } \\
\text { Kanada. }\end{array}$ & Anacardiaceae & Kireçli & $\mathrm{Az}$ & $\begin{array}{l}\text { Haziran- } \\
\text { Temmuz }\end{array}$ \\
\hline 40 & $\begin{array}{l}\text { Robinia } \\
\text { hispida L. } \\
9.06 .2019 \\
\text { MDŞ 1580. }\end{array}$ & $\begin{array}{l}\text { Pembe çiçekli } \\
\text { akasya }\end{array}$ & Ağaç & $\begin{array}{l}\text { Kuzey } \\
\text { Amerika, } \\
\text { güneydoğu } \\
\text { Amerika. }\end{array}$ & Leguminosae & Kumlu-Tınlı & $\mathrm{Az}$ & $\begin{array}{l}\text { Haziran- } \\
\text { Temmuz }\end{array}$ \\
\hline 41 & $\begin{array}{l}\text { Robinia } \\
\text { pseudoacaci } \\
a \text { L. } \\
9.06 .2019 \\
\text { MDŞ 1581. }\end{array}$ & Yalancı akasya & Ağaç & $\begin{array}{l}\text { Türkiye } \\
\text { Karadeniz, } \\
\text { Avrupa, Güney } \\
\text { Afrika ve } \\
\text { Amerika. }\end{array}$ & Leguminosae & Kumlu-Killi & $\mathrm{Az}$ & $\begin{array}{l}\text { Haziran- } \\
\text { Temmuz }\end{array}$ \\
\hline 42 & $\begin{array}{l}\text { Robinia } \\
\text { pseudoacaci } \\
a \\
\text { L.“umbracu } \\
\text { lifera" } \\
06.06 .2019, \\
\text { MDŞ } 1625\end{array}$ & Top akasya & Ağaç & Amerika & Leguminosae & Kumlu-Killi & $\mathrm{Az}$ & $\begin{array}{l}\text { Haziran- } \\
\text { Temmuz }\end{array}$ \\
\hline 43 & $\begin{array}{l}\text { Salix } \\
\text { babylonica } \\
\text { L. } \\
04.05 .2019, \\
\text { MDŞ 1626 }\end{array}$ & Salkım söğüt & Ağaç & Çin, Türkiye & Salicaceae & Kumlu-Killi & Fazla & $\begin{array}{l}\text { Nisan- } \\
\text { Mayis }\end{array}$ \\
\hline 44 & $\begin{array}{l}\text { Salix caprea } \\
\text { L. } \\
04.05 .2019, \\
\text { MDS } 1627\end{array}$ & $\begin{array}{l}\text { Sarkık keçi } \\
\text { söğüdü }\end{array}$ & Ağaç & $\begin{array}{l}\text { Asya, Avrupa } \\
\text { ve Türkiye }\end{array}$ & Salicaceae & Kumlu-Killi & Fazla & $\begin{array}{l}\text { Mart- } \\
\text { Nisan }\end{array}$ \\
\hline
\end{tabular}




\begin{tabular}{|c|c|c|c|c|c|c|c|c|}
\hline 45 & $\begin{array}{l}\text { Sophora } \\
\text { japonica L. } \\
06.07 .2019 \text {, } \\
\text { MDŞ } 1629\end{array}$ & Japon soforası & Ağaç & $\begin{array}{l}\text { Japonya, Kore } \\
\text { ve Çin }\end{array}$ & Fabaceae & Humuslu & $\mathrm{Az}$ & $\begin{array}{l}\text { Temmuz- } \\
\text { Ağustos }\end{array}$ \\
\hline 46 & $\begin{array}{l}\text { Sophora } \\
\text { japonica } \mathrm{L} . \\
\text { "pendula" } \\
06.07 .2019, \\
\text { MDŞ } 1628 \\
\end{array}$ & Sarkık sofora & Ağaç & Japonya & Fabaceae & Humuslu & Orta & $\begin{array}{l}\text { Temmuz- } \\
\text { Ağustos }\end{array}$ \\
\hline 47 & $\begin{array}{l}\text { Tilia } \\
\text { arg1entea } \\
\text { Desf.Ex DC. } \\
06.07 .2019, \\
\text { MDŞ 1630 } \\
\end{array}$ & $\begin{array}{l}\text { Gümüşi } \\
\text { ıhlamur }\end{array}$ & Ağaç & $\begin{array}{l}\text { Güneydoğu } \\
\text { Avrupa, Batı } \\
\text { Asya }\end{array}$ & Tiliaceae & Kumlu-Killi & Orta & $\begin{array}{l}\text { Haziran- } \\
\text { Temmuz }\end{array}$ \\
\hline 48 & $\begin{array}{l}\text { Tilia } \\
\text { tomentosa } \\
\text { Moench. } \\
\text { 06.07.2019, } \\
\text { MDŞ 1624 }\end{array}$ & Ihlamur & Ağaç & $\begin{array}{l}\text { Güneydoğu } \\
\text { Avrupa ve Batı } \\
\text { Asya }\end{array}$ & Tiliaceae & Kumlu-Killi & Orta & $\begin{array}{l}\text { Haziran- } \\
\text { Temmuz }\end{array}$ \\
\hline 49 & $\begin{array}{l}\text { Abies } \\
\text { nordmanni } \\
\text { ana ssp. } \\
\text { bornmülleri } \\
\text { ana Mattf. } \\
3.06 .2019 \text {, } \\
\text { MDŞ } 1541 \text {. }\end{array}$ & Uludağ göknarı & $\begin{array}{l}\text { İbreli } \\
\text { Ağaç }\end{array}$ & $\begin{array}{l}\text { Bafra-Uludağ } \\
\text { arası, Orta } \\
\text { Karadeniz, } \\
\text { Kuzeybatı } \\
\text { Anadolu }\end{array}$ & Pinaceae & Kumlu & Fazla & Nisan? \\
\hline 50 & $\begin{array}{l}\text { Cedrus } \\
\text { atlantica } \\
\text { Manetti."gla } \\
\text { uca" } \\
9.04 .2019, \\
\text { MDŞ 1582. }\end{array}$ & $\begin{array}{l}\text { Mavi atlas } \\
\text { sediri }\end{array}$ & $\begin{array}{l}\text { İbreli } \\
\text { Ağaç }\end{array}$ & $\begin{array}{l}\text { Himalayalar, } \\
\text { Afganistan, } \\
\text { Kuzey Afrika, } \\
\text { Fas, Cezayir ve } \\
\text { Atlas dağları }\end{array}$ & Pinaceae & $\begin{array}{l}\text { Kumlu-Killi- } \\
\text { Kireçli }\end{array}$ & $\mathrm{Az}$ & Nisan? \\
\hline 51 & $\begin{array}{l}\text { Cedrus } \\
\text { deodora } \\
\text { G.Don. } \\
\text { 04.04.2019, } \\
\text { MDŞ 1620 } \\
\end{array}$ & $\begin{array}{l}\text { Himalaya } \\
\text { sediri }\end{array}$ & $\begin{array}{l}\text { İbreli } \\
\text { Ağaç }\end{array}$ & $\begin{array}{l}\text { Afganistan'dan } \\
\text {, Nepal'e kadar }\end{array}$ & Pinaceae & $\begin{array}{l}\text { Kumlu-Killi- } \\
\text { Kireçli }\end{array}$ & Orta & Nisan? \\
\hline 52 & $\begin{array}{l}\text { Cedrus } \\
\text { atlantica } \\
\text { Manetti. } \\
\text { "glauca" } \\
\text { pendula } \\
08.09 .2019 \text {, } \\
\text { MDŞ } 1622\end{array}$ & $\begin{array}{l}\text { Sarkık atlas } \\
\text { sediri }\end{array}$ & $\begin{array}{l}\text { İbreli } \\
\text { Ağaç }\end{array}$ & $\begin{array}{l}\text { Kuzey } \\
\text { Afrika'daki } \\
\text { Atlas dağları }\end{array}$ & Pinaceae & kozmopolit & Orta & $\begin{array}{l}\text { Eylül- } \\
\text { Ekim? }\end{array}$ \\
\hline 53 & $\begin{array}{l}\text { Cedrus } \\
\text { libani } \\
\text { A.Rich. } \\
\text { 08.09.2019, } \\
\text { MDŞ 1621 } \\
\end{array}$ & Toros sediri & $\begin{array}{l}\text { İbreli } \\
\text { Ağaç }\end{array}$ & $\begin{array}{l}\text { Türkiye ve } \\
\text { Lübnan }\end{array}$ & Pinaceae & Kireçli & $\mathrm{Az}$ & $\begin{array}{l}\text { Eylül - } \\
\text { Ekim? }\end{array}$ \\
\hline 54 & $\begin{array}{l}\text { Cupressus } \\
\text { arizonica } \\
\text { Greene } \\
\text { "Glauca” } \\
3.06 .2019 \text {, } \\
\text { MDŞ } 1546 .\end{array}$ & $\begin{array}{l}\text { Mavi Arizona } \\
\text { servisi }\end{array}$ & $\begin{array}{l}\text { İbreli } \\
\text { Ağaç }\end{array}$ & $\begin{array}{l}\text { Meksika ve } \\
\text { Arizona'nın } \\
\text { dağlık } \\
\text { bölgeleri }\end{array}$ & Cupressaceae & Kireçli & $\mathrm{Az}$ & $\begin{array}{l}\text { Şubat- } \\
\text { Mart }\end{array}$ \\
\hline 55 & $\begin{array}{l}\text { Cupressus } \\
\text { sempervire } \\
\text { ns L. } \\
\text { "Glauca" } \\
04.04 .2019 \text {, }\end{array}$ & Mavi adi servi & $\begin{array}{l}\text { İbreli } \\
\text { Ağaç }\end{array}$ & $\begin{array}{l}\text { Güney Avrupa, } \\
\text { Batı Asya }\end{array}$ & Cupressaceae & Killi-Kumlu & $\mathrm{Az}$ & Nisan \\
\hline
\end{tabular}




\begin{tabular}{|c|c|c|c|c|c|c|c|c|}
\hline & MDŞ 1623 & & & & & & & \\
\hline 56 & $\begin{array}{l}\text { Cupressocy } \\
\text { paris } \\
\text { leylandii } \\
\text { ML.Green } \\
9.04 .2019 \text {, } \\
\text { MDŞ } 1583 .\end{array}$ & Melez servi & $\begin{array}{l}\text { İbreli } \\
\text { Ağaç }\end{array}$ & Yaygın & Cupressaceae & $\begin{array}{l}\text { Kumlu } \\
\text { balçık } \\
\text { topraklar }\end{array}$ & Orta & Nisan \\
\hline 57 & $\begin{array}{l}\text { Cupressus } \\
\text { sempervire } \\
n s \text { L. } \\
\text { "Stricta" } \\
04.04 .2019 \text {, } \\
\text { MDŞ } 1598 .\end{array}$ & Sütun servi & $\begin{array}{l}\text { İbreli } \\
\text { Ağaç }\end{array}$ & $\begin{array}{l}\text { Akdeniz } \\
\text { Bölgesi }\end{array}$ & Cupressacea & $\begin{array}{l}\text { Kumlu } \\
\text { balçlk } \\
\text { topraklar }\end{array}$ & Orta & Nisan \\
\hline 58 & $\begin{array}{l}\text { Ilex } \\
\text { aquifolium } \\
\text { L. "aurea } \\
\text { marginata" } \\
\text { 7.05.2019, } \\
\text { MDŞ 1547. }\end{array}$ & Çoban püskülü & Çalı & $\begin{array}{l}\text { Avrupa, Batı } \\
\text { Asya ve Kuzey } \\
\text { Afrika }\end{array}$ & Aquifoliaceae & $\begin{array}{l}\text { Kumlu- } \\
\text { Kireçli }\end{array}$ & Orta & Mayıs \\
\hline 59 & $\begin{array}{l}\text { Juniperus } \\
\text { virginiana } \\
\text { L. } \\
\text { "Skyrocket" } \\
04.05 .2019 \text {, } \\
\text { MDŞ } 1599 .\end{array}$ & Sütun ardıç & $\begin{array}{l}\text { İbreli } \\
\text { Ağaç }\end{array}$ & Yaygın & Cupressaceae & Kireçli & $\mathrm{Az}$ & - \\
\hline 60 & $\begin{array}{l}\text { Picea } \\
\text { glauca } \\
\text { (Moench.)V } \\
\text { oss. Conica } \\
04.05 .2019 \text {, } \\
\text { MDŞ } 1600 .\end{array}$ & Konik ladin & $\begin{array}{l}\text { İbreli } \\
\text { Ağaç }\end{array}$ & Kuzey Amerika & Pinaceae & Kumlu-Killi & Çok & - \\
\hline 61 & $\begin{array}{l}\text { Picea } \\
\text { excelsa } \\
\text { (Lam.)Link. } \\
\text { 04.05.2019, } \\
\text { MDŞ 1601. }\end{array}$ & Batı ladini & $\begin{array}{l}\text { İbreli } \\
\text { Ağaç }\end{array}$ & Avrupa & Pinaceae & Humuslu & Orta & Mayıs \\
\hline 62 & $\begin{array}{l}\text { Picea } \\
\text { pungens } \\
\text { Engelm."Gl } \\
\text { auca } \\
\text { Hopsii" } \\
04.05 .2019 \text {, } \\
\text { MDŞ 1602. }\end{array}$ & Mavi ladin & $\begin{array}{l}\text { İbreli } \\
\text { Ağaç }\end{array}$ & $\begin{array}{l}\text { Batı ve Kuzey } \\
\text { Amerika }\end{array}$ & Pinaceae & Humuslu & Orta & Mayıs \\
\hline 63 & $\begin{array}{l}\text { Pinus nigra } \\
\text { J.F.Arnold. } \\
6.05 .2019 \text {, } \\
\text { MDŞ 1584. }\end{array}$ & Karaçam & $\begin{array}{l}\text { İbreli } \\
\text { Ağaç }\end{array}$ & $\begin{array}{l}\text { Akdeniz, Ege, } \\
\text { İç Anadolu } \\
\text { Bölgesi }\end{array}$ & Pinaceae & $\begin{array}{l}\text { Kumlu, killi, } \\
\text { kireçli }\end{array}$ & $\mathrm{Az}$ & Mayıs \\
\hline 64 & $\begin{array}{l}\text { Taxus } \\
\text { baccata L. } \\
\text { "fastigiata" } \\
\text { 8.06.2019, } \\
\text { MDŞ 1548. }\end{array}$ & Sütun porsuk & $\begin{array}{l}\text { İbreli } \\
\text { Ağaç }\end{array}$ & $\begin{array}{l}\text { İrlanda, } \\
\text { Karadeniz ve } \\
\text { Amanos } \\
\text { Dağları }\end{array}$ & Taxaceae & Humuslu & Orta & Nisan \\
\hline 65 & $\begin{array}{l}\text { Thuja } \\
\text { orientalis L. } \\
4.04 .2019 \text {, } \\
\text { MDŞ } 1585 .\end{array}$ & Mazı & Çalı & $\begin{array}{l}\text { Kuzey Çin, } \\
\text { Hindistan, } \\
\text { Kore, Japonya, } \\
\text { İran }\end{array}$ & Cupressaceae & Balçıklı & Fazla & $\begin{array}{l}\text { Mart,Nisa } \\
\mathrm{n}\end{array}$ \\
\hline 66 & $\begin{array}{l}\text { Thuja } \\
\text { orientalis L. } \\
\text { "Compacta" } \\
\text { 15.03.2019, } \\
\text { MDŞ } 1617\end{array}$ & $\begin{array}{l}\text { Altuni top } \\
\text { doğu mazısı }\end{array}$ & $\begin{array}{l}\text { İbreli } \\
\text { Ağaç }\end{array}$ & $\begin{array}{l}\text { İran, Çin, } \\
\text { Japonya, Kore }\end{array}$ & Cupressaceae & Kozmopolit & Orta & Mart \\
\hline
\end{tabular}




\begin{tabular}{|c|c|c|c|c|c|c|c|c|}
\hline 67 & $\begin{array}{l}\text { Thuja } \\
\text { orentalis L. } \\
\text { "Pyramidali } \\
\text { s aurea" } \\
\text { 15.03.2019, } \\
\text { MDŞ } 1618\end{array}$ & $\begin{array}{l}\text { Altuni piramit } \\
\text { mazı }\end{array}$ & $\begin{array}{l}\text { İbreli } \\
\text { Ağaç }\end{array}$ & $\begin{array}{l}\text { Doğu Asya, } \\
\text { Kuzey Amerika }\end{array}$ & Cupressaceae & Kumlu,Killi & Orta & Mart \\
\hline 68 & $\begin{array}{l}\text { Berberis } \\
\text { thunbergii } \\
\text { DC. var. } \\
\text { atropurpur } \\
\text { ea } \\
05.05 .2019 \text {, } \\
\text { MDŞ } 1603\end{array}$ & $\begin{array}{l}\text { Kırmızı } \\
\text { yapraklı } \\
\text { kadıntuzluğu }\end{array}$ & Çalı & Çin, Japonya & Berberidaceae & Kumlu-Killi & $\mathrm{Az}$ & Mayıs \\
\hline 69 & $\begin{array}{l}\text { Berberis } \\
\text { veitchii } \\
\text { C.K.Schneid } \\
\text { 05.05.2019, } \\
\text { MDŞ } 1616\end{array}$ & $\begin{array}{l}\text { Herdemyeşil } \\
\text { kadıntuzluğu }\end{array}$ & Çalı & Hubei, Çin. & Berberidaceae & Kumlu-Killi & $\mathrm{Az}$ & Mayıs \\
\hline 70 & $\begin{array}{l}\text { Buddleja } \\
\text { davidii } \\
\text { Franch. } \\
05.06 .2019, \\
\text { MDŞ } 1619\end{array}$ & Kelebek çalısı & Çalı & Çin, Japonya & Scrophulariaceae & Kumlu-Killi & Orta & $\begin{array}{l}\text { Haziran- } \\
\text { Temmuz }\end{array}$ \\
\hline 71 & $\begin{array}{l}\text { Cornus alba } \\
\text { L. Sibirica } \\
05.06 .2019, \\
\text { MDŞ } 1604\end{array}$ & Kızılcık & Çalı & $\begin{array}{l}\text { Sibirya,Kuzey } \\
\text { Kore, } \\
\text { Mançurya }\end{array}$ & Cornaceae & Humuslu & Orta & Haziran \\
\hline 72 & $\begin{array}{l}\text { Cotoneaster } \\
\text { franchetii } \\
\text { Boiss. } \\
9.05 .2019, \\
\text { MDŞ } 1548 .\end{array}$ & Dağ muşmulası & Çalı & $\begin{array}{l}\text { Kuzey Myanma } \\
\text { r ve } \\
\text { kuzey Tayland' } \\
\text { da,güneybatı Çi } \\
\text { n }\end{array}$ & Rosaceae & Kumlu-Killi & Orta & Temmuz \\
\hline 73 & $\begin{array}{l}\text { Cotoneaster } \\
\text { horizontalis } \\
\text { Decne. } \\
05.06 .2019 \text {, } \\
\text { MDŞ 1593. }\end{array}$ & Dağ muşmulası & Çalı & Çin & Rosaceae & Kozmopolit & Orta & $\begin{array}{l}\text { Mayıs- } \\
\text { Haziran }\end{array}$ \\
\hline 74 & $\begin{array}{l}\text { Cydonia } \\
\text { japonica } \\
\text { Thunb. } \\
\text { 05.05.2019, } \\
\text { MDŞ 1597. } \\
\end{array}$ & $\begin{array}{l}\text { Süs } \\
\text { ayvası,Bahar } \\
\text { dalı }\end{array}$ & Çalı & Japonya & Rosaceae & Humuslu & Orta & Nisan \\
\hline 75 & $\begin{array}{l}\text { Forsythia } \\
\text { intermedia } \\
\text { Zab. } \\
\text { 15.03.2019, } \\
\text { MDŞ 1606. } \\
\end{array}$ & Altınçanak & Çalı & Çin & Oleaceae & Kozmopolit & Orta & Mart \\
\hline 76 & $\begin{array}{l}\text { Juniperus } \\
\text { horizontalis } \\
\text { Mnch. } \\
15.03 .2019 \text {, } \\
\text { MDŞ 1605. }\end{array}$ & Yatık ardıç & Çalı & Kuzey Amerika & Cupressaceae & Kozmopolit & $\mathrm{Az}$ & - \\
\hline 77 & $\begin{array}{l}\text { Juniperus } \\
\text { sabina L. } \\
10.05 .2019, \\
\text { MDŞ } 1549 .\end{array}$ & Sabin ardıcı & Çalı & $\begin{array}{l}\text { Türkiye'de } \\
\text { Kuzey ve } \\
\text { Güney } \\
\text { Anadolu'nun } \\
\text { yanısıra, Orta } \\
\text { ve Güney } \\
\text { Avrupa, Kırım, } \\
\text { Batı Kafkasya }\end{array}$ & Cupressaceae & Kireçli & Orta & \\
\hline
\end{tabular}




\begin{tabular}{|c|c|c|c|c|c|c|c|c|}
\hline & & & & ve İran & & & & \\
\hline 78 & $\begin{array}{l}\text { Ligustrum } \\
\text { japonicum } \\
\text { Thunb. } \\
05.06 .2019, \\
\text { MDŞ } 1607\end{array}$ & $\begin{array}{l}\text { Herdemyeşil } \\
\text { kurtbağrı }\end{array}$ & Çalı & $\begin{array}{l}\text { Japonya ve } \\
\text { Kore }\end{array}$ & Oleaceae & Humuslu & Orta & $\begin{array}{l}\text { Haziran- } \\
\text { Temmuz }\end{array}$ \\
\hline 79 & $\begin{array}{l}\text { Mahonia } \\
\text { aquifolium } \\
\text { Nutt. } \\
\text { 15.03.2019, } \\
\text { MDŞ } 1615\end{array}$ & Mahonya & Çalı & Kuzey Amerika & $\underline{\text { Berberidaceae }}$ & Humuslu & Orta & $\begin{array}{l}\text { Mart- } \\
\text { Nisan }\end{array}$ \\
\hline 80 & $\begin{array}{l}\text { Pyracantha } \\
\text { coccinea } \\
\text { Roem. } \\
05.06 .2019, \\
\text { MDŞ } 1614\end{array}$ & Ateş dikeni & Çalı & $\begin{array}{l}\text { Türkiye ve } \\
\text { Güney Avrupa }\end{array}$ & Rosaceae & $\begin{array}{l}\text { Humuslu- } \\
\text { Kumlu-Killi } \\
\text { (Karışık) }\end{array}$ & Orta & $\begin{array}{l}\text { Haziran- } \\
\text { Temmuz }\end{array}$ \\
\hline 81 & $\begin{array}{l}\text { Rosa sp. L. } \\
05.06 .2019 \text {, } \\
\text { MDŞ } 1608 .\end{array}$ & Gül & Çalı & Doğu Asya & Rosaceae & $\begin{array}{l}\text { Humuslu, } \\
\text { killi,kumlu }\end{array}$ & Orta & $\begin{array}{l}\text { Haziran- } \\
\text { Temmuz }\end{array}$ \\
\hline 82 & $\begin{array}{l}\text { Sambucus } \\
\text { nigra } \mathrm{L} . \\
05.06 .2019, \\
\text { MDŞ } 1610\end{array}$ & Mürver & Çalı & $\begin{array}{l}\text { Kuzey Avrupa, } \\
\text { Kuzey Amerika }\end{array}$ & Caprifoliaceae & $\begin{array}{l}\text { Kumlu- } \\
\text { Balçıklı }\end{array}$ & Fazla & $\begin{array}{l}\text { Mayıs- } \\
\text { Haziran- } \\
\text { Temmuz }\end{array}$ \\
\hline 83 & $\begin{array}{l}\text { Spiraea } x \\
\text { bumalda } \\
\text { Burv. } \\
05.06 .2019, \\
\text { MDŞ } 1620 .\end{array}$ & $\begin{array}{l}\text { Pembe çiçekli } \\
\text { keçisakalı }\end{array}$ & Çalı & $\begin{array}{l}\text { Japonya, Çin ve } \\
\text { Kore }\end{array}$ & Rosaceae & Kumlu & Fazla & $\begin{array}{l}\text { Haziran- } \\
\text { Temmuz }\end{array}$ \\
\hline 84 & $\begin{array}{l}\text { Spiraea } \\
\text { vanhouttei } \\
\text { Zab. } \\
05.06 .2019, \\
\text { MDŞ } 1609\end{array}$ & $\begin{array}{l}\text { Beyaz çiçekli } \\
\text { keçisakalı }\end{array}$ & Çalı & $\begin{array}{l}\text { Kanada, } \\
\text { Amerika, Çin. }\end{array}$ & Rosaceae & $\begin{array}{l}\text { Kireçli, } \\
\text { Kumlu }\end{array}$ & Orta & $\begin{array}{l}\text { Mayıs- } \\
\text { Haziran }\end{array}$ \\
\hline 85 & $\begin{array}{l}\text { Syringa } \\
\text { vulgaris L. } \\
04.04 .2019, \\
\text { MDŞ } 1613\end{array}$ & Leylak & Çalı & $\begin{array}{l}\text { Güneydoğu } \\
\text { Avrupa }\end{array}$ & Oleaceae & Kozmopolit & $\mathrm{Az}$ & $\begin{array}{l}\text { Nisan- } \\
\text { Mayıs }\end{array}$ \\
\hline 86 & $\begin{array}{l}\text { Weigela sp. } \\
\text { Thunb. } \\
\text { 15.05.2019, } \\
\text { MDŞ } 1611\end{array}$ & Gelin tacı & Çalı & Doğu Asya & Caprifoliaceae & Kumlu, killi & Orta & $\begin{array}{l}\text { Mayıs, } \\
\text { Haziran }\end{array}$ \\
\hline 87 & $\begin{array}{l}\text { Viburnum } \\
\text { opulus L. } \\
\text { "sterile" } \\
\text { 15.05.2019, } \\
\text { MDŞ } 1622 .\end{array}$ & Kartopu & Çalı & $\begin{array}{l}\text { Avrupa, Kuzey } \\
\text { Afrika, Orta } \\
\text { Asya }\end{array}$ & Adoxaceae & Humuslu & Orta & $\begin{array}{l}\text { Mayıs, } \\
\text { Haziran }\end{array}$ \\
\hline 88 & $\begin{array}{l}\text { Viburnum } \\
\text { tinus L. } \\
\text { 10.06.2019, } \\
\text { MDŞ } 1549 .\end{array}$ & $\begin{array}{l}\text { Herdemyeşil } \\
\text { kartopu }\end{array}$ & Çalı & $\begin{array}{l}\text { Avrupa, Kuzey } \\
\text { Afrika }\end{array}$ & Adoxaceae & Humuslu & Orta & $\begin{array}{l}\text { Şubat, } \\
\text { Mart, } \\
\text { Nisan, } \\
\text { Kasım, } \\
\text { Aralık }\end{array}$ \\
\hline 89 & $\begin{array}{l}\text { Agapanthus } \\
\text { sp. L'Her. } \\
05.06 .2019 \text {, } \\
\text { MDŞ } 1592 .\end{array}$ & Agapanthus & $\begin{array}{l}\text { Çok } \\
\text { ylllık } \\
\text { otsu }\end{array}$ & Afrika & Amaryllidaceae & Humuslu & Fazla & $\begin{array}{l}\text { Haziran, } \\
\text { Temmuz, } \\
\text { Ağustos }\end{array}$ \\
\hline
\end{tabular}




\begin{tabular}{|c|c|c|c|c|c|c|c|c|}
\hline 90 & $\begin{array}{l}\text { Carex sp. L. } \\
5.05 .2019, \\
\text { MDŞ } 1587 .\end{array}$ & Büyük göl sazı & $\begin{array}{l}\text { Çok } \\
\text { yllık } \\
\text { otsu }\end{array}$ & Yaygin & Cyperaceae & $\begin{array}{l}\text { Bataklık, } \\
\text { kireçli, sulu } \\
\text { topraklar }\end{array}$ & Fazla & Mayıs \\
\hline 91 & $\begin{array}{l}\text { Hemerocalli } \\
s \text { sp. L. } \\
10.06 .2019, \\
\text { MDŞ } 1550 .\end{array}$ & Hemerokallis & $\begin{array}{l}\text { Çok } \\
\text { ylllık } \\
\text { otsu }\end{array}$ & $\begin{array}{l}\text { Çin, Kore, } \\
\text { Japonya }\end{array}$ & Asphodelaceae & Kumlu,Killi & Orta & $\begin{array}{l}\text { Mayıs- } \\
\text { Ağustos }\end{array}$ \\
\hline 92 & $\begin{array}{l}\text { Iris sp. L. } \\
\text { 5.05.2019, } \\
\text { MDŞ } 1556 .\end{array}$ & Süsen & $\begin{array}{l}\text { Çok } \\
\text { yllık } \\
\text { otsu }\end{array}$ & $\begin{array}{l}\text { Kuzey } \\
\text { yarımküre. }\end{array}$ & Íridaceae & Kumlu,Killi & Orta & $\begin{array}{l}\text { Mart- } \\
\text { Nisan }\end{array}$ \\
\hline 93 & $\begin{array}{l}\text { Lavandula } \\
\text { angustifolia } \\
\text { Miller } \\
6.05 .2019 \text {, } \\
\text { MDŞ } 1586 .\end{array}$ & Lavanta & $\begin{array}{l}\text { Çok } \\
\text { yllık } \\
\text { otsu }\end{array}$ & $\begin{array}{l}\text { İspanya, } \\
\text { Fransa, İtalya, } \\
\text { Hırvatistan }\end{array}$ & Lamiaceae & Kozmopolit & Orta & $\begin{array}{l}\text { Haziran, } \\
\text { Temmuz, } \\
\text { Ağustos }\end{array}$ \\
\hline 94 & $\begin{array}{l}\text { Kniphofia } \\
\text { sp. Moench. } \\
6.06 .2019, \\
\text { MDŞ } 1553 .\end{array}$ & Kniphofia & $\begin{array}{l}\text { Çok } \\
\text { yllık } \\
\text { otsu }\end{array}$ & Afrika & Asphodelaceae & Humuslu & $\mathrm{Az}$ & $\begin{array}{l}\text { Haziran, } \\
\text { Temmuz }\end{array}$ \\
\hline 95 & $\begin{array}{l}\text { Nymphaea } \\
\text { alba L. } \\
6.06 .2019, \\
\text { MDŞ } 1551 .\end{array}$ & Nilüfer & $\begin{array}{l}\text { Çok } \\
\text { yllık } \\
\text { otsu }\end{array}$ & Misir & Nymphaeaceae & Humuslu & Fazla & $\begin{array}{l}\text { Haziran, } \\
\text { Temmuz }\end{array}$ \\
\hline 96 & $\begin{array}{l}\text { Typha } \\
\text { angustifolia } \\
\text { L. } \\
\text { 10.05.2019, } \\
\text { MDŞ 1555. }\end{array}$ & Saz & $\begin{array}{l}\text { Çok } \\
\text { yllık } \\
\text { otsu }\end{array}$ & Yaygın & Typhaceae & Bataklık & Fazla & $\begin{array}{l}\text { Mayıs- } \\
\text { Ağustos }\end{array}$ \\
\hline 97 & $\begin{array}{l}\text { Festuca } \\
\text { ovina L. } \\
\text { 6.06.2019, } \\
\text { MDŞ } 1557 .\end{array}$ & $\begin{array}{l}\text { Çim(Koyun } \\
\text { yumağı) }\end{array}$ & $\begin{array}{l}\text { Tek } \\
\text { veya } \\
\text { çok } \\
\text { ylllık } \\
\text { otsu }\end{array}$ & $\begin{array}{l}\text { Avrupa, } \\
\text { Türkiye }\end{array}$ & Poaceae & Kozmopolit & Orta & $\begin{array}{l}\text { Ekim, } \\
\text { Kasım }\end{array}$ \\
\hline 98 & $\begin{array}{l}\text { Poa } \\
\text { pratensis L. } \\
6.06 .2019, \\
\text { MDŞ 1558. }\end{array}$ & $\begin{array}{l}\text { Çim(Çayır } \\
\text { salkımotu) }\end{array}$ & $\begin{array}{l}\text { Çok } \\
\text { ylllkk } \\
\text { otsu }\end{array}$ & $\begin{array}{l}\text { Anadolu, } \\
\text { Avrupa, Asya, } \\
\text { Kuzey Afrika }\end{array}$ & Poaceae & Kozmopolit & Orta & $\begin{array}{l}\text { Mayıs, } \\
\text { Haziran }\end{array}$ \\
\hline 99 & 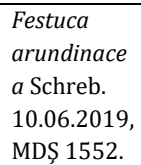 & $\begin{array}{l}\text { Çim(Kamışsı } \\
\text { yumak) }\end{array}$ & $\begin{array}{l}\text { Çok } \\
\text { ylllık } \\
\text { otsu }\end{array}$ & Avrupa & Poaceae & Kozmopolit & Orta & $\begin{array}{l}\text { Mayıs, } \\
\text { Haziran }\end{array}$ \\
\hline
\end{tabular}




\section{Sonuçlar, Tartışma ve Öneriler}

Uşak İli Atapark Parkı nezlinde Uşak Peyzaj florasını araştırmak amacıyla yapılan bu araştırmada, 39 familyaya ait 99 takson tespit edilmiştir. Familyaların içerdiği takson sayıları şöyledir; Aceraceae 5, Hippocastanaceae 1, Betulaceae 4, Bignonaceae 1, Fabaceae 8, Anacardiaceae 1, Rosaceae 15, Elaeagnaceae 1, Oleaceae 3, Gingkgoaceae 1, Malvaceae 1, Sapindaceae 1, Hamamelidaceae 1, Magnoliaceae 1, Moraceae 1, Platanaceae 2, Fagaceae 2, Salicaceae 2, Tiliaceae 2, Pinaceae 5, Cupressaceae 10, Aquafoliaceae 1, Pinaceae 4, Taxaceae 1, Berberidaceae 3, Scrophulariaceae 1, Cornaceae 1, Oleaceae 2, Caprifoliaceae 2, Adoxaceae 2, Amaryllidaceae 1, Cyperaceae 1, Asphodelaceae 1, Iridaceae 1, Lamiaceae 1, Asphodelaceae 1, Nymphaeaceae 1, Typhaceae 1, Poaceae 4 takson içermektedir. Bu taksonlardan 26 sı kültivar, 70 i tür, 2 alt tür, 1 varyete katagorisindedir. Bitki taksonlarının bitki formasyonlarına göre dağılımı ise şöyledir: Yaprak döken ağaç 48, İbreli ağaç 17, Çalı 23, Çok yıllık otsu 11 taksondur. Bitki taksonların toprak isteğine göre dağılımı ise; Kumlu-killi 32, kumlu 4, humuslu 14, kozmopolit 14, kireçli 5, balçık topraklar 10, kumlu balçık topraklar 3, humuslu 2, killi, kumlu 2, kumlu, kireçli 2, Su kenarı, sulu ortam 2 taksondur. Bitki taksonlarının anavatanlarına göre dağımı; Asya kökenli 25, Türkiye-Avrupa kökenli 23, Amerika kökenli 18, Yaygın 32, Sadece Türkiye kökenli 3 taksondur. Bitki taksonlarının su isteği; 18 takson fazla, 56 takson orta, 20 taksonun az su isteği vardır. Bitki taksonlarının mevsimlere göre çiçek açma zamanına bakıldığında, 54 takson ilkbaharda, 33 takson yaz mevsiminde, 3 takson sonbaharda, uzun süreli çiçekli olan ise 1 takson vardır [14].

Bitki taksonlarının anavatanları veya doğal yayılış alanlarına göre bakıldığında, Asya kökenli 25 takson, Türkiye-Avrupa kökenli 23 takson, Amerika kökenli 18 takson, yaygın olan 32 takson, sadece Türkiye kökenli 3 takson bulunmaktadır (Tablo 2). Uşak ili iklimi Emberger'e göre [8], kıșı soğuk, yarı kurak, Akdeniz İklimi özelliklerini göstermesi, nedeniyle bu iklime uyan takson sayılarının artırılması, bitkilerin adaptasyonları ve ekolojik istekleri, ekonomik kaygılar göz önüne alındığında yaygın ve iklime uyabilen Türkiye kökenli taksonların sayılarının artırılması daha iyi olacaktır.

Atapark peyzaj florasında bulunan taksonların su ihtiyacı değerlendirildiğinde, 56 takson orta, 20 takson az, 18 takson fazla su ihtiyacı göstermektedir. Küresel ısınma ile gelecek yıllarda bitkilerin su ihtiyaçlarının artacağı ve küresel iklim değişikliğinin süs bitkilerini olumsuz etkileyeceği göz önüne alındığında [15], su ihtiyacı fazla olan ilkbaharın son ayları ve yaz dönemi kuraklığı, bu peyzaj bitki taksonları için sorun oluşturabilir. Bu bitki taksonlarının dikimleri yerine, daha fazla kserofit bitki dikilebilir. Doğal flora içerisinde uzun ömürlü, su ihtiyacı fazla olmayan, çiçekli durma süresi fazla olan bitkiler peyzaj bitkisi olarak kullanılabilir.

Floradaki bitkilerin toprak ihtiyaçlarını analiz sonuçları ile karşılaştırdığımızda, Kumlukilli 32, kumlu 4, humuslu 14, kozmopolit 14, kireçli 5, balçık topraklar 10, kumlu balçı topraklar 3, humuslu 2, killi, kumlu 2, kumlu, kireçli 2, Su kenarı, sulu ortam 2 takson olduğu görülmekte iken, toprak analizi sonucu Atapark'ta bitkilerin bulunduğu toprak yapısı, kum oranı fazla olan kumlu-killi-tındır. Bu toprak yapısı kumlu-killi, toprak yapısı isteği olan taksonlar için elverişli iken, toprak isteği kireçli, balçık, humuslu taksonlar 
için toprak bakımından ekolojik isteklerini karşılamamakta, bu durum fizyonomilerini etkilemektedir (Tablo 1) [16].

\section{Kaynaklar}

1. Karadağ A. Kentsel ekoloji. Kentsel Çevre Analizlerinde Coğrafi Yaklaşım. Ege Coğrafya Dergisi, İzmir, 2009;18/(1-2):31-47.

2. Türk Dil Kurumu Sözcükleri 2020. URL: Sözlük gov.tr. Erişim tarihi:06.10.2020.

3. Öztan Y, Arslan M. İç Anadolu Bölgesi Ekolojik Koşullarına Uygun Sukulent (Etli Yapraklı) Bitki Türlerinden Peyzaj Mimarlığı çalışmalarında Yer örtücü Olarak Yararlanma Olanakları. Tisamat Basımevi, 1992. Ankara.

4. Bahçe çiçeklerinin peyzaj mimarlı̆̆ı çalışmalarında kullanım alanları, seçimini etkileyen etmenler ve tasarım örnekleri URL: https://acikders.ankara.edu.tr/pluginfile.php/107123/mod_resource/content/0/3.hafta. pdf. Erişim tarihi:06.10.2020.

5. Gül A, Özçelik H, Uzun ÖF. Isparta Yöresindeki Bazı Doğal Yer Örtücü Bitkilerin Adaptasyonu ve Özellikleri, Süleyman Demirel Üniversitesi, Fen Bilimleri Enstitüsü Dergisi. 2012;16-2(2012):133-145.

6. Anonim. Uşak Belediyesi, Park ve Bahçeler Müdürlüğü verileri. 2019. Uşak.

7. Dönmez Şahin M, Serin M. Bulkaz Dağının (Sivaslı-Uşak) Fulorası. Ot Sistematik Botanik Dergisi, 2009; 16-2. (97-128).

8. Akman Y. İklim ve Biyoiklim, Palme Yayın Dağıtım, 1990. Ankara.

9. Bouyoucos GJ. A recalibration of the hydrometer method for making mechanical analysis of the soils. Agronomy Journal. 1955;4(9):434.

10. Bouyoucos GJ. "Hydrometer Metod Improved for Making Particle, Size Analysis of Soil." Agronomy Journal, 1962. Vol.54.No:5,21.

11. Özer Z, Tursun N, Önen H, Uygur FN, Erol D. "Herbaryum Yapma Teknikleri ve Yabanci Ot Teshis Yöntemleri", Gaziosmanpasa Üniversitesi, Ziraat Fakültesi Yayınları, 1998. No:22, Kitaplar Serisi No: 12, Tokat, $214 \mathrm{~s}$.

12. Davis PH. Flora of Turkey and the East Aegean Islands. 1965-1988. Vol.1-IX and supp. Edinburg Üniv. Press UK

13. Davis PH. Turkey: Present Stads of Floristic Knowledge. Dep. Of Botany at Royal Bot. Garden. 1975. Edinburg Üniv.

14. Erken E. Peyzaj Bitkileri ve Özellikleri (Angiospermae), Cinius Yayınları, 2014. İstanbul.

15. Uzunoğlu F, Bayazit S, Mavi K. Küresel İklim Değişikliğinin Süs Bitkileri Yetiştiriciliğine Etkisi. Mustafa Kemal Üniversitesi, Ziraat Fakültesi Dergisi, 2015;20(2):66-75.

16. Zengin M, Özbahçe, A. Bitkilerin Iklim ve Toprak Istekleri. Atlas Kitabevi, 2011.Konya. 